\title{
TENTATIVA DE APROXIMAÇÃO EM LITERATURA COMPARADA: A MODERNIZAÇÃO NA LITERATURAS CHINESA E BRASILEIRA CONTEMPORÂNEAS.
}

O estudo aprofundado e um contacto mais esteito com o processo de modernização cultural chinês e, em particular, com a Revolução Literária de 1917 apresenta, para os estudiosos do Ocidente e, particularmente, da America Latina, um avançado grau de interesse.

Primeiramente, porque esse movimento coloca em tela questões gerais da maior importância no plano da teoria literária e das ciências políticas, quais sejam: o papel da arte, da cultura e da literatura em particular, no processo histórico; o papel da vanguarda dentro desse processo; e os problemas linguísticos, de alta complexidade, da padronização ou da generalização da terminologia e do vocabulário em bases internacionais, à luz de processos sociais, que tendem a levar as sociedades a níveis de homogeneização cultural e organizativa em escala, até o nosso século, inédito no Mundo.

Para os estudiosos da América Latina, e do Brasil em especial, no entanto, o movimento literário chinês em 1917 se reveste, ainda, de outras características que chamam particularmente a atenção e o interesse. Desde logo, o instigante paralelismo que pode ser traçado entre esse movimento e os movimentos contemporâneos da America Latina, tais como o da negritude, no qual a America Latina compartilha com a África uma realização cultural de tipo novo e revolucionário, e nosso próprio movimento modernista, do qual não só os aspectos das inovações linguiísticas, como das próprias influências, guardam similitudes altamente prometedoras com a Revolução Literária Chinesa de 1917

Ao colocar desta forma a possibilidade destes paralelismos e abrir, por assim dizer, a perspectiva de um acompanhamento da evolução de cada movimento, da sua dinâmica interna, da sua evolução subsequente e de seus desdobramentos, que não são necessariamente culturais, literários ou artísticos, mas sim sócio-políticos, o paralelismo dos mo- 
vimentos chinês e latino-americanos parece um manancial até certo ponto novo, capaz de elucidar e, provavelmente, de aprofundar algumas questões centrais da dependência, ainda muito pouco analisadas em todas as suas conseqüêencias pelos países pertencentes ao chamado Terceiro Mundo.

\section{HISTÓRIC.O}

A Revolução Literária Chinesa de 1917 se inscreve no quadro de um movimento mais amplo de modernização desencadeądo na China a partir do final do século XIX. Os parâmetros dentro dos quais se desenvolveu esse movimento mais geral são, cada dia, mais universalmente conhecidos. Atravessa a China, a partir da metade do século XIX, um período bastante peculiar em sua história, caracterizado por uma presença cada vez mais marcante do dominador ou ocupante estrangeiro, sob a forma das nações ocidentais imperialistas que, em ritmo crescente, impunham ao império manchú processos de dominação e expoliação de características, às vezes, dramáticas. $\mathrm{O}$ império, por seu lado, seguia professando o velho princípio de organização, secularmente instaurado na China e que, tem sido dito, fora responsável pela manutenção da unidade da nação chinesa, da sua resistência à inovação e à dominação estrangeira e também de sua relativa auto-suficiência cultural, caracterizada com frequiência e talvez, nem sempre com justeza, principalmente pelos ocidentais, como isolamento. No século XIX e principalmente na segunda metade ou final desse século, atravessava o império chinês, em função de fatores históricos mais recentes, quais sejam, a dominação estrangeira, as dissensões internas, as conjunturas sucessivas desfavoráveis a sua economia que haviam, inclusive, propiciado o desencadeamento de revoltas de grande vulto que solapavam as bases da nação, um período bastante crítico.

No quadro dos problemas enfrentados nesse período, a formulação tradicional do Estado chinês, baseado na preeminência e no papel hegemônico de um estamento social de natureza burocrática e de características funcionais e de formação, por assim dizer, programada, não se mostrava à altura de tratar com eficiência, muito menos com eficácia, os desafios emergentes. Num mundo onde a componente tecnológica cada vez mais se tornava um ingrediente necessário do poder e da dominação e um instrumento na mão de potências necessitadas da ampliação, a níveis universais, do mercado para sua produção industrial, então em plena expansão, a formação tradicional do estamento hegemônico da sociedade chinesa, o mandarimato, baseada na cultura literária, na habilidade para uma escrita de um alto grau de complexidade, no uso de uma linguagem de grande refinamento e com elevada dosagem de códigos mostrava-se inoperante. 
O exemplo histórico próximo, do Japão, nação cuja similitude com alguns aspectos do império chinês, inclusive quanto a questões de tradição, não pode ser ignorado, mas que, no período em questão, enveredava decididamente por um caminho de modernização à ocidental, joga também um papel decisivo no início de uma revisão cultural e política que se processa na China, na segunda metade do século XIX. Desde logo, que uma característica fundamental da cultura e da civilização chinesas passa a assumir nesse processo em seu início uma posição de relevo não encontrável em outras culturas; trata-se da língua e, particularmente, da escrita chinesa, cujas peculiaridades, de se tratar de uma língua dissociada em níveis diferenciados, o erudito e o popular, o erudito cristalizado em torno de fórmulas literárias, secularmente exploradas e codificadas e dotado de uma escrita igualmente refinada, se mostrava de todo avessa à incorporação ou ao tratamento de problemas, por assim dizer, da modernidade. Por outro lado, o divórcio da cultura oficial, em termos de língua e de escrita, das formas e das construções das estruturas linguísticas da população, revelavam outra componente da dificuldade do império chinês de ingressar no processo de modernização: a ausência de um instrumento hábil de incorporar ao domínio das letras toda uma população para que esta pudesse, através desse domínio, se qualificar intelectualmente e tecnicamente para a absorção e o manejo da tecnologia. E, então, por dois aspectos que a cultura literária chinesa se mostra em defasagem acentuada, no início do processo de modernização, ou seja, a incorporação do conhecimento em vias de universalização, baseada no domínio das ciências naturais, do qual surgira a tecnologia moderna ocidental e, de outro, a dificuldade da incorporação de grandes massas da população a níveis de habilidade tecnológica mínima para a sustentação de um processo de organização de base industrial da sociedade e da economia.

Não estranha, portanto, que os primeiros indícios de um processo de modernização ocorressem na China, no século XIX, associados a necessidades de natureza estratégica militar, sob a forma da criação de uma escola de tradução de idiomas ocidentais para o chinês, dentro de um complexo militar, no caso, um arsenal. A gritante superioridade dos armamentos ocidentais em relação aos antiquíssimos armamentos do exército chinês engendraram, desde logo, a preocupação de um mínimo de equiparação da possibilidade do domínio desses armamentos; daí que o surgimento da escola de traduções junto ao arsenal seja significativo desta primeira e mais gritante dissociação entre estágios de desenvolvimento tecnológico. Destes, que são sintomas iniciais de uma preocupação de modernização, logo se poderá verificar a sua extensão a um só setor, até certo ponto próximo e, ainda, um setor institucional; é dentro exatamente da corte e do mandarinato, durante um período efêmero, que surge, já caracterizado como movimen- 
to de modernização e traduzido na proposição da tentativa de implantação de inúmeras reformas de natureza político-econômica, um novo indício de expansão dos propósitos modernizadores, antes sintomatizados. Este primeiro momento, dentro do processo de modernização, se caracteriza pelo que foi chamado de auto-fortalecimento, e esse próprio conceito já traduz o princípio embutido na ideologia do movimento. A assimilação da tecnologia ocidental para fins militares e, eventualmente, administrativos, a rejeição concomitante da assimilação de outros elementos da cultura ocidental, visando às finalidades modernizadoras.

E contemporâneo desse movimento o aumento do número de estudantes chineses que se dirigem a outros países ocidentais e particularmente ao Japão. Retornando à terra natal, esses chamados retur. ned studentes já iriam se distinguir dentro da intelectualidade formada na tradição do mandarinato, como um grupo mais propenso à inovação, dotado de maior inquietação, inclusive em função da discriminação que sofria no acesso a posições eminentes nos quadros do mandarinato. Dentro deste contexto é que se desencadeia, em 1898, o movimento da reforma, idealizado e desenvolvido por inteiro no âmbito da administração imperial e tendo a encabeçá-los os intelectuais $K^{\prime}$ an $Y u$-wei (1858-1927) e Lián Ch'i-Ch'ao (1873-1929), originários ambos de Shántun, província que, na China, mais contactos mantivera com o Ocidente, em função de sua posição geográfica. Os influxos ocidentais são eminentes na obra e nas colocações dos líderes do movimento da reforma de 1898, não só estudiosos, como divulgadores do pensamento de grandes filósofos ocidentais como Kant, Hegel, Francis Bacon, e outros do enciclopedismo francês e dos movimentos, então contemporâneos; do Positivismo e do Evolucionismo. K'an Yu-wei e Lián Ch'iCh'ao, dentro da forte propensão peculiar à tradição literária chinesa, também divulgam suas concepções através de dramas, de feitura sem dúvida canhestra, nos quais formas dramáticas chinesas se conjugam com a presença de personagens e expedientes tipicamente acidentais, em particular, dos italianos.

O movimento de reforma, no entanto, também se comporta muito mais como um indício do processo sócio-econômico que adviria, do que como realização efetiva. Derrotado no âmbito da administração imperial da corte, com seus líderes politicamente banidos do movimento, não chega a agregar ao cambaleante sistema de governo chinês de então qualquer novo fator de resistência. $O$ império se irá desagregando crescentemente, quer sob o efeito da dominação e das pressões das potências ocidentais, quer sob a ausência de um mínimo de unidade interna que lhe garanta a possibilidade de ação política e administrativa, até 1912, quando irá entrar no colapso definitivo da mo- 
narquia. No breve período do movimento de reforma até os desdobramentos políticos mais avançados da segunda década do século, no entanto, o movimento de contacto e de início de divulgação do pensamento ocidental, e aí incluída sua literatura e sua cultura artística, na China, avança também por outras fontes. Proliferam nesses períodos as traduções de clássicos da economia política, da filosofia e da literatura ocidentais, através da obra de tradutores como $Y$ en $F u$ (18531921) e Lin Shu (1852-1924) A própria produção literária chinesa da época, já influenciada pelas obras traduzidas, começa a apresentar temas, personagens e enredos ligados a uma problemática até então inédita na história chinesa, a exemplo do problema da mulher, no qual se rebatem as posições das feministas anglosaxãs de então. E intensíssima nesse período a discussão que se trava entre intelectuais chineses a respeito de questões fundamentais sobre o papel da arte, da cultura e da literatura e como essas produções se ligam aos interesses superiores da sociedade. A vinculação de tipo ético da literatura às funções sociais, de forma paradoxal, presente na cultura chinesa tradicional, na medida em que esta fazia da literatura e do conhecimento literário, do domínio das técnicas e dos códigos literários, condição básica da programação com que se criava e se mantinha o estamento dos mandarins, os burocratas letrados a quem competia o exercício das funções de governo e que, no entanto, por força mesmo daqueles códigos e princípios de composição, fugia, ou tendia a fugir, com frequência, de uma colocação material precisa da problemática social e econômica, passa a ser um tema dominante. A questão de se a arte e a literatura servem à construção ética e à programação dos valores éticos ou a uma expressão, por assim dizer, objetiva dos fatos da realidade, que se coloca, por sinal, em inúmeras ocasiões em outras culturas e outras literaturas, se coloca nesse período da história chinesa e da sua cultura, de forma marcante. Os próprios conceitos da individualidade, do subjetivismo, perfilados no romantismo literário ocidental, fazem então sua erupção no cenário chinês em contraposição à visão clássica ortodoxa da cultura chinesa e do sistema político, de que a literatura devia se servir para o encaminhamento à via moral, à via reta do Confucionismo.

A polêmica que se trava entre os intelectuais chineses da época em torno de questões como essa é alimentada e se baseia no aparecimento de uma cópia numerosa de periódicos, de publicações culturais, nas quais esses assuntos encontram o seu canal de debate. Como há de acontecer, porém, em todos os movimentos literários de renovação, alguns protagonistas e alguns textos ganham posição eminente, como uma espécie de divisor de águas entre a produção e as colocações de um período pré-revolucionário e as de um período de realização decidida da reformulação propugnada para a litera- 
tura e a cultura geral da China. No caso da Revolução Literária de 1917, os protagon istas centrais são Chen $\mathrm{Tu}$-hsiu e $\mathrm{Hu}$-Shih. O primeiro, um intelectual, encarregado de uma revista cultural intitulada Juventude Nova, tendo formada sua concepção literária principalmente dentro das linhas de pensamento desenvolvidas na França a partir da revolução de 1789, autor de traduções de novelas de autores russos, bem como de Oscar Wilde, publica em 1915 o artigo intitulado Uma Discussão da História da Literatura Européia Moderna. No debate que esse artigo polêmico vem a provocar, faz a sua entrada em cena o escritor $\mathrm{Hu} S \mathrm{Sh}$, de formação diametralmente oposta à de Chen Tu-hsiu. Estudante nos Estados Unidos da América do Norte, aluno de John Dewey e orientado filosoficamente nas direções opostas, apolíticas, do pragmatismo, da problemática metodológica, aderente no plano literário à corrente dos imagistas como Amy Lowell, publica um artigo intitulado Oito Pontos Sobre o Que Não fazer em Literatura. Esse artigo virá a se constituir, vis-à-vis os artigos de Chen- Tu-hsiu já citados, nos parâmetros básicos do desencadeamento da Revolução Literária Chinesa. Toda uma crítica, fundamentada na avaliação e numa releitura dos clássicos chineses se encontra presente nesse trabalho que, no entanto, dentro das concepçōes filosóficas perfiladas por seu autor, não se limita à demonstração das inoperâncias, das obsolescências da literatura chinesa clássica, transformada já no século XIX e no início do presente século, em mera conformação acadêmica, de formas cristalizadas, de terminologia anacrônica, de construções tornadas sediças, à força de sua repetição e da procura de variações cada vez mais difíceis em torno de imagens e temas singulares e, por fim, desligada, por todas essas características, de uma penetração e um contacto mais amplo e uma influenciação em círculos amplos da população. Trata, também, de apresentar o lado alternativo, qual seja, os caminhos pelos quais se haveria de substituir esta literatura ultrapassada e obsoleta por uma literatura aderente aos interesses e à problemática do tempo presente.

Em que pesem suas origens e suas concepções filosóficas e literárias divergentes, senão antagônicas, $H u$ Shih e Chen $T u$-hsiu engajam-se na crista da Revolução Literária, numa mesma linha comum, de ataque ao tradicionalismo e ao emprego abusivo, codificado, de fórmulas literárias, à falta de abrangência da temática da produção literária, ao seu caráter elitista, aos seus preconceitos no tratamento da linguagem comum da população; com eles engajam-se outros protagonistas da Revolução Literária. Entre esses, há os de formação e pensamento bastante diversificados, em particular no que tange às influências ocidentais em sua formação, desde os moldados na escola alemã no período romântico, aos de derivação mais fortemente literária, principalmente a partir da literatura russa realista e naturalista, 
até os formados à luz da problemática política e das colocações doutrinárias dos italianos do Rissorgimento. E possível encontrar-se, no entanto, como já ocorrera entre o pensamento de Chen $\mathrm{Tu}$-hsiu e $\mathrm{Hu}$ Shih, no conjunto dos protagonistas da Revolução Literária, um núcleo comum de preocupação e postura, que se poderia dizer predominante, voltado para o realismo e para o utilitarismo. E fácil traçar a origem desses princípios e sua ligação com o nacionalismo de origem européia, o liberalismo de origem anglo-saxônica e verificar a sua tradução como método de luta através do pragmatismo, do ceticismo e do agnosticismo. Na Revolução Literária Chinesa, no entanto, todo esse conjunto de princípios doutrinários e posturas filosóficas terá como alvo maior o elemento comum formado pelo tradicionalismo e pelo Confucionismo, em torno dos quais se formulara simbioticamente toda a preparação e a manutenção do sistema de governo e de toda a produção literária de natureza erudita.

Posteriormente à eclosão da Revolução Literária Chinesa, as diversas concepções de seus participantes voltarão a se fazer presente e evoluirão por linhas diversificadas e, aí, marcadamente antagônicas, em alguns casos. N'sso tampouco se peculiariza a Revolução Literária Chinesa. Processos semelhantes podem ser verificados, inclusive, no Modernismo brasileiro; mas talvez o elemento que, no caso chinês, mais nitidamente conduza a esta abertura em leque de posturas doutrinárias e filosóficas, no período de maturação subsequiente à Revolução Literária, é a associação, num determinado momento, desta Revolução com o movimento político, extremamente significativo na história chinesa, que é o movimento 4 de Maio. O contacto, dentro de uma prática política e social, da Revolução Literária com o movimento amplamente participado por segmentos diversos da população chinesa, com certeza propicia àquela Revolução uma prática de suas propostas quanto ao estilo, à composição, quanto ao emprego da linguagem popular, ao mesmo tempo que um crivo de seu arsenal doutrinário, cujas malhas são os componentes políticos da situação então vivida pelo país. O movimento 4 de Maio, que se desencadeia em 1919, tem por origem a reação chinesa às condições fortemente desvantajosas para o país, incorporadas no Tratado de Paz de Versalhes. Acompanhando, através do noticiário proveniente de Versalhes, as proposições e a postura assumidas, face ao Tratado, pelos representantes do governo chinês, os estudantes de Changai desencadeiam fortes manifestações de rua contra o que reputam omissão do governo chinês na defesa dos interesses do país, sua subserviência aos interesses e ao descaso com que as potências ocidentais, na partilha do botim do apósguerra, tratam a nação chinesa, colocando-se portanto em luta contra o governo como um todo, e a direção da Universidade, em particular, num primeiro momento. 
E então que são alvos do seu ataque as autoridades, os eminentes mandarins, que detêm posições de comando político as mais destacadas no governo e cujo comprometimento com as posturas omissas e vacilantes da Conferência de $\mathrm{Paz}$ em Versalhes se faz evidente.

Na luta pela rejeição dos termos do Tratado inúmeros outros aspectos passam a ser levantados pelos estudantes, desde os que atingem a sua própria prática universitária e as insuficiências do sistema de ensino e da organização institucional da Universidade até aspectos de natureza econômica e social, que fazem com que o movimento se estenda a setores dos trabalhadores, a entidades interessadas em direitos humanos, a entidade femininas e, por fim, a setores empresariais. $\mathrm{Na}$ mesma medida, de um movimento de natureza urbana e limitado a apenas uma cidade, este se estende e se apresenta com ocorrências semelhantes ao original em outras cidades e regiōes. Culminando numa paralização generalizada da atividade econômica, com a participação do empresariado, dos trabalhadores, da intelectualidade, o 4 de Maio atinge os seus objetivos com a recusa da delegação chinesa, por fim, em assinar os termos do Tratado de Paz, a sua retirada, o seu abandono da Conferência de Versalhes, a demissão pelo governo de ministros e autoridades universitárias comprometidas com o tradicionalismo, que se colocaram em oposição à luta estudantil e da população e com o desencadeamento de uma série de posições combativas em torno de temas sociais, através de fundações, associações, entidades culturais de diversos tipos.

Não menor como efeito do desencadeamento do movimento 4 de Maio é a repercussão que os princípios esposados pela Revolução Literária logram junto aos setores engajados mais decididamente na luta política, dos quais se destacam os partidos Chin Pu Tán e Min Tán, este liderado por Sun Yat Sen e que, em texto de 1920, expressa sua total concordância e reputa o valor político dos princípios esposados pelos intelectuais protagonistas da Revolução Literária. Há já, no texto de Sun Yat Sen, um nexo muito claro entre as posturas da Revolução Literária e a de renovação política e social, que se coloca como tema da ação dos líderes revolucionários republicanos do país. No período que se segue ao triunfo do movimento 4 de Maio, as polêmicas da $\mathrm{Re}-$ volução Literária, a difusão dos seus princípios, transferem-se do mero plano do debate para o plano da realização. São, por assim dizer, institucionalizados os princípios e as propostas da Revolução Literária no quadro institucional que se segue, na década de 20 , com a ascensão ao poder do Kuo Min Tán e com a incorporação, mais formal que efetiva, dos princípios reformadores da literatura, tanto na educação, quanto na cultura oficial. Mais e mais, durante este período, os protanistas da Revolução Literária e os novos intelectuais chineses vão ten- 
tanto se alinhar, seguindo princípios doutrinários e de ação política divergentes e diversificados.

Dá evidência disso a proliferação das correntes literárias dos anos 20, na China, com a Sociedade de Estudos Literários, postulando o realismo na arte e sua colocação a serviço da vida e do sofrimento dos humilhados e oprimidos; a Sociedade Criação, fundada em 1922, postulando um programa puramente estético, de arte pela arte e, naturalmente, em oposição à corrente anterior; a Sociedade da Lua Crescente, formada por escritores de tendência liberal, entre os quais $\mathrm{Hu}$ Shih, pregando a máxima liberdade de expressão dentro dos limites do pudor; a Sociedade dos Tecelóes de Palavras, seguindo um programa liberal semelhante ao da escola anterior; a Sociedade Sem Nome; a Sociedade do Sol, e outras, aderentes a diversas correntes literárias. $O$ agrupamento e a convergência de concepções diversas em torno de um núcleo de posicionamento ativo de combate cultural e político verificado na Revolução Literária, não se irá reproduzir doravante na história chinesa; mais e mais as concepções e alinhamentos dos intelectuais se darão dentro das linhas que, a partir dos anos 20 até o período mais recente, irão polarizar o processo político chinês.

\section{TEMAS E ASPECTOS DOUTRINÁRIOS - UNIVERSALIDADE E PECULIARIDADE NA REVOLUÇÃO LITERÁRIA CHINESA}

Uma das peculiaridades que tornam a análise da Revolução Literária Chinesa de particular interesse, quer para o estudioso da teoria literária, quer para o estudioso das ciências políticas, é o grau avançado e extremamente ilustrativo em que esse movimento apresenta a correlação entre as posturas reformadoras e inovadoras em relação à língua e à literatura e as posturas políticas. Este aspecto de imbricação do fato cultural no fato político não está ausente dos movimentos modernistas e de renovação e revolução literárias do presente século; no entanto, é na China que ele alcança o seu grau mais estremado de clareza. Isso se deve, essencialmnte, à existência na China, secularmente, daquele que foi considerado, por diversos pensadores, o modo asiático de produção, o sistema que se realizou muito cedo na história chinesa, de uma verdadeira teoria da administração, de natureza estamental, formada por processos codificados, programados, de natureza bastante sagaz, que asseguraram a perpetuação, a permanência, durante muitos séculos, do estamento mandarim como hegemônico, na condução dos assuntos do Estado e a peculiaridade de ser este sistema inteiramente articulado a um processo de formação e distinção do letrado como elemento do governo dotado de uma posição social específica, qual seja de administrar, e tendo a sua formação amparada essencialmente 
no domínio da técnica literária, da cultura clássica e dos códigos dentro dos quais esta se processava.

Nessas condições, a problemática colocada pela necessidade de uma superação da linguagem e da literatura tradicionais com vistas à incorporação do desenvolvimento científico e tecnológico, presente, evidente, em inúmeras literaturas em processo de modernização, no final do século passado e início do presente, se coloca, no caso chinês, como fator fortemente estruturador. Certamente que os movimentos modernistas dos países ocidentais e dos países do Terceiro Mundo no sentido de reformular a literatura e a língua culta não têm sentido puramente estético, ou sentido puramente artístico, criativo. Essa proposta se liga a propostas, no mínimo, de modernização no aspecto político, no aspecto econômico, no aspecto social. No caso chinês, porém, esta proposta não se pode dizer que esteja ligada apenas a um processo de simples modernização, mas ao contrário ela traz em seu cerne a derrubada do sistema do mandarinato. Ela é a negação da infra-estrutura básica em que se assenta toda a doutrina de governo do Estado chinês tradicional. Ela, é, por isso, claramente e fortemente política, desde seu início. Trata-se, como em outros movimentos, de enriquecer a literatura e fazê-la retornar a suas origens vitais, através da incorporação do falar e da construção linguíistica popular. A ques. tão da retomada do vernáculo na Revolução Literária Chinesa, está indissoluvelmente ligada à postura de ampliar o quadro da participação da população chinesa na condução dos assuntos do país e na estruturação e no desempenho da sua economia.

Uma segunda componente, especificamente chinesa, do problema da Revolução Literária, é a que poderịa ser encontrada na peculiar situação de seus protagonistas e da intelectualidade chinesa em geral, voltada, em sua formação, essencialmente para o desempenho das funções de governo, para o acesso à carreira burocrática e que, no quadro da crise que se abate sobre o Império, a partir do início deste século até seu colapso em 1912, se coloca na posição de um estamento em crise do ponto de vista social, com contingentes crescentes marginalizados da acessibilidade social, se emparelhando com outros elementos ou setores da população. Até certo ponto paradoxalmente, esta postura, por assim dizer profissional que, sem dúvida, joga também um papel no engajamento de setores da intelectualidade chínesa no movimento revolucionário literário é a que mais prontamente se verá anulada e ameaçada pelo próprio triunfo da Revolução Literária. Na verdade, realizar o ideário da Revolução Literária significava negar ao intelectual o acesso burocraticamente estabelecido e institucionalizado a posição de eminência no contexto social e de comando na administração e processo político. Significava a sua incorporação 
sob outras formas, liberais, necessariamente assalariadas, mas não de estamento privilegiado, no quadro de uma sociedade liberal e democrática. A estes aspectos, cuja peculiaridade chinesa é indiscutível, ainda que ilustrando de forma extremada situações menos nítidas em outros movimentos de modernização literária, há que ter presente, na interpretação do movimento chinês de 1917 e 1919, aqueles aspectos, por assim dizer, universais, com questões teóricas, que se colocam em relação à literatura e à criação artística em geral, pari passu ao processo político.

O movimento se desencadeia, adquire sua fase de maturidade, ao longo de um período em que a monarquia é ainda um fato dominante em relação ao qual se há de posicionar o contexto político chinês, e ao se dizer monarquia, se estará falando de mandarinato. Mesmo com o sul divorciado, em 1912, é ainda a postura monárquica ou republicana que continua a centralizar a colocação política do país durante o período que se segue, quando se expande plenamente a colocação da Revolução Literária, primeiramente com a tentativa de açambarcamento do poder pelo caudilho militarista Yuan Chi Kai, que chega a se proclamar imperador em 1916, numa restauração da monarquia, e depois, no período subsequiente a sua derrocada, o esfacelamento do poder entre os chefes regionais, os chamados senhores da guerra.

O quadro político assim colocado dificilmente abriga a pespectiva das grandes correntes pelas quais deverá optar a história chinesa posteriormente. Mas é, no entanto, o movimento literário que antecipa este quadro de alternativas possíveis e de grandes questões a serem elucidadas. $O$ problema da generalização da educação que está indissociavelmente vinculado a uma postura modernizadora, seja ela liberal, da conformação de um mercado de mão de obra, em condições de gerir um processo econômico modernizado, seja uma perspectiva mais avançada de natureza social, de tendência socialista; a preocupação com os segmentos da população via de regra mantidos à margem, quer como protagonistas, quer como interessados, do processo literário tem, na verdade, o significado premonitório do reconhecimento da presença das grandes massas da população como protagonistas políticos, e este é maìs um aspecto desencadeado e expresso com antecipação pela Revolução Literária.

Seria possível colocar, ainda, dentro dos aspectos gerais, que pertencem mais ao campo da teoria literária, a questão denotada pela Revolução Literária Chinesa, do papel de vanguarda. No entanto, queremos crer que este aspecto, no caso do movimento em questão, pode ser mais amplamente elucidado quando colocado no âmbito de uma problemática já não universal do ponto de vista da teoria literária e da ciência política, mas dentro de uma problemática já mais de- 
limitada, correspondente à questão dos movimentos de modernização cultural e renovação literária nos países do Terceiro Mundo, dentro do qual vão se dar as ocorrências de forte paralelismo entre o movimento chinês e os movimentos latino-americanos, e brasileiro, em particular, do Modernismo, que parecem abrir atraentes caminhos de investigação.

\section{OS PARALELOS INSTIGANTES - OS MOVIMENTOS DE RENOVAÇÃO LITERÁRIA E CULTURAL DO TERCEIRO MUNDO}

Neste campo, o quadro de concordâncias e similitudes entre o movimento revolucionário cultural chinês em 1917 e 1919 e o Modernismo brasileiro é excitante. Não fosse por sua contemporaneidade, ambos desencadeados com pouquíssimos anos de intervalo, mas essencialmente por outros e variados aspectos. Esses vão desde o seu próprio desencadeamento ao papel das culturas polarizadas em processo de renovação face aos centros de polarização cultural do mundo de então, como também à presença de protagonistas significativos. Em ambos os casos, apresentam-se em dupla os condutores dos movimentos, constituindo-se, por assim dizer, em divisores de água, cada um com suas características peculiares: de um lado os demolidores das concepçōes e formulaçōes tradicionais (Oswald de Andrade, Chen Tu hsiu), de outro os releitores da cultura tradicional e popular, engajados em posturas construtivas e sistematizadoras, como num contraponto dialético necessário para que o movimento se expanda e se realize em sua plenitude. Tratemos de explicar cada um desses aspectos separadamente. De início, o papel da Vanguarda: para o estudioso pouco familiarizado com a língua chinesa, será até certo ponto surpreendente encontrar na produção de alguns dos protagonistas da Revolução Literária, não só uma frequentação e um conhecimento, como uma influência direta dos expoentes de vanguarda da produção poética do início do século. E o caso por exemplo do autor Kuo Mo Jo, no texto Adorador de Ídolos, de forte ressonância futurista e que em sua colocação, em sua expressão ideológica face ao mundo em processo de difusão da tecnologia e de superação de barreiras culturais, lembra, em verdade, o Álvaro de Campos, da celebração dos fatos trazidos à vivência, por assim dizer universal, das populações através do jornal; a noção de que tudo se passa simultaneamente, a vida, a morte, os acidentes geográficos, os grandes emprendimentos públicos, os conflitos, o verdadeiro contraponto da Ode Triunfal de Fernando Pessoa, expresso em chinês. Coincidentemente esta presença futurista, mostra-se também marcante na obra de Mário de Andrade e de outros modernistas brasileiros sendo apenas um dos elementos da vanguarda da produção 
literária européia a se fazer presente, não sendo ocioso lembrar o próprio Blaise Cendrars, Cocteau e outros, cuja ressonância nos movimentos da renovação é forte, estruturadora e, se poderia dizer, até certo ponto, obsessiva em alguns aspectos, ainda que ressalvada a qualidade literária propriamente dita da produção de origem, da produção por ela influenciada, no bojo dos movimentos de modernização.

Nesse aspecto, colocações aceitáveis, até certo ponto comprováveis têm sido feitas. Efetivamente, a vanguarda na China, como na América Latina, em particular no Brasil - gerada no curso de um processo de modernização da cultura dos países centrais do Ocidente, que não coloca em questão a própria posição hegemônica desses países e siquer os seus sistemas político-sociais - tem, no entanto, para os países periféricos do Terceiro Mundo, um papel estratégico essencial. Ela rompe com codificações, com critérios de valores historicamente assentados, estaticamente venerados como elementos de dominação imperialista externa e interna, como elemento de estagnação do avanço histórico a nível interno. Explicite-se, na medida em que a Vanguarda investe contra a linguagem tradicional, contra as formas poéticas literárias perfeitamente codificadas, oficiais ou oficiosamente aceitas como normas em países do Terceiro Mundo, ela cria as condições para a colocação em xeque das oligarquias locajs e esse é muito o caso da América Latina e é muito o caso brasileiro, em particular. Não se trata aqui de uma postura de independência frente a uma metrópole que, historicamente, é um processo superado, mas se trata de investir ou de romper um dos aspectos do aparelho ideológico de Estado, que garante a dominação das oligarquias, que é exatamente a cultura oficial, a cultura acadêmica. Na China, não se pode falar de uma oligarquia, mas de um sistema de governo incrivelmente duradouro em termos de tempo, historicamente enraízado por séculos, delimitador e limitador, em grau extremado, das possibilidades de incorporação de fatores sociais no processo político e de governo, que é, então, afetado num de seus aparelhos mais fortes, ou seja, a língua e a construção literária, por uma formulação que vem reforçada pela liberdade experimentada e propugnada pela Vanguarda. Esta Vanguarda, portanto, chega de suas origens centrais, hegemônicas, como mais um produto, assim posto a consumo da Periferia, com uma conotação essencialmente conservadora, portanto, mas que se transfigura face ao contexto local, criando fermentações que, em última análise, desembocarão na superação de fatores de estagnação internos; e num desencadeamento de processos políticos mais avançados, que irão, em última análise, romper ou se confrontar com as próprias relações de dominação que propiciaram a presença das Vanguardas, desenvolvidas nos países centrais, junto aos movimentos de renovação cultural nos países periféricos. 
Há uma outra componente associada a esse aspecto - não necessariamente à Vanguarda - que é a divulgação do conhecimento nos países periféricos das formas avançadas do pensamente filosófico e das diferentes colocações, alternativas, do ponto de vista de proposição social, política e econômica engendradas nos países centrais; muito menos do que o refletir uma visão de um simples consumo de uma produção intelectual gerada e ligada ao quadro de interesses da hegemonia dos países centrais, esta difusão do pensamento ocidental, do pensamento dos países centrais hegemônicos, com todas suas contradições, ao se transpor, no bojo dos movimentos de renovação e revolução literária desencadeada nos países periféricos, abre para esses as portas da universalidade, da sua incorporação $\mathrm{n}_{\mathrm{O}}$ grande contugente de temas e opções que se colocam mundialmente e, principalmente, para os países centrais. Rompe-se, dessa forma, as limitações de natureza regional, de natureza social, permitindo a inserção dos periféricos numa problemática, que vai engendrar, quando posteriormente reelaborada, posturas de confrontação com os próprios países centrais em sua hegemonia. O paralelo que se poderia traçar nesse aspecto é a própria função das línguas ocidentais nos países colonizados do continente africano. A língua do colonizador funcionando como elemento de aglutinação de forças agregadas de forma heterogênea, díspar, por sistemas tribais, ou de clãs, ou de castas, em um todo político de características nacionais e de posturas independentes. E aqui o paralelo entre os movimentos de modernização cultural do Brasil e da China continua sendo instigante. Veja-se como deriva do Modernismo brasileiro uma grande parte da confrontação política e das alternativas em que se irá estruturar a vida política do país nos anos subsequientes. Uma parte dos protagonistas do movimento modernista se filiando ao movimento tenentista, expressão das idéias e da presença da pequena burguesia liberal brasileira no quadro político, em contraposição às oligarquias regionais. Isso se contrapõe, quase que analogamente, ao engajamento dos ex-protagonistas da Revolução Literária Chinesa, nas correntes do Kuo Min Tan e, posteriormente, a partir dos anos $20 \mathrm{em}$ diante, na corrente revolucionária socialista chinesa.

Ainda no quadro desses paralelismos, observe-se o problema que ganha destaque, da língua erudita em contraposição à língua vernácula. Todo o trabalho desencadeado no Modernismo, principalmente por Mário de Andrade, se aparente muito fortemente ao trabalho de IIu Shih no bojo da Revolução Literária Chinesa. Não apenas a proposição vaga, genérica, mas o próprio empenho em demonstrar os caminhos para essa realização, presente em ambos os autores. Esse aspecto pode nos levar à colocação de outro paralelismo, a presença concomitante dos autores que propugnam ou que se empenham, antes de tudo, na realização da crítica e na demolição das estruturas de pen- 
samento oficiais, presentes no país, em contraposição ou em complementação à presença daqueles que, provavelmente em posturas mais conservadoras, dedicam-se a uma sistematização e à proposição dos caminhos pelos quais se há de estruturar a nova cultura nas bases dos princípios que propõem.

Se o paralelismo entre $H u$ Shih e Mário de Andrade é evidente, não o é menos o que se poderia traçar entre Kuo Mo Jo ou Chen Tu hsiu e Oswald de Andrade, contrapontos estruturalmente significativos de um e outro movimento. Já no campo da realização da Revolução Literária e de seus métodos, há que notar mais o paralelismo e a preocupação, evidentes em $H u$ Shih e em Mário de Andrade, com a releitura e com a crítica objetiva da produção literária acariciada e prestigiada pelo sistema de governo dominante; no caso brasileiro toda a exegese da obra dos parnasianos mais reconhecidos, de Francisca Júlia a Olavo Bilac e, no caso de $H u$ Shih, a releitura dos clássicos, inclusive dos clássicos escritos em liłteratura vernácula e a sua reavaliação e redescoberta. A contraposição entre os elementos de maior pendor crítico e de maior pendor sistemático parece constituir uma componente indispensável da realização do processo renovador.

\section{CONCLUSÕES MUITO TRANSITÓRIAS}

A enumeração dos aspectos que abre à consideração do estudioso latino-americano a Revolução Literária chinesa de 1917, e os paralelismos que entre esse movimento e os movimentos modernistas da América Latina podem ser traçados, logo demonstram a inviabilidade de que se tirem conclusões definitivas a respeito de aspectos parciais ou de características gerais dos movimentos culturais em pauta. Há, na verdade, um campo bastante grande a ser explorado, que possibilitará, inclusive, criticar-se algumas pistas que ora parecem prometedoras, ao menos ao nível da análise literária comparada.

Conclusão evidente, a nível preliminar, que pode ser retida no entanto, é a de que maior quantidade de textos correspondentes ao movimento literário ch nnês de 1917 devem ser colocados à disposição ou em condições de serem objeto do estudo da intelectualidade brasileira. Mais que eventuais similitudes ou caminhos aparentemente atraentes ora apontados, ou que venham a sê-lo futuramente, será a própria presença desses textos que dará margem, em trabalhos sucessivos, à exploração das veredas hoje precariamente abertas ao conhecimento, na compreensão de culturas, por tantos títulos, tão díspares quanto a latino-americana e a brasileira em particular, e a chinesa, não obstante objeto de processos e enquadramentos históricos tão comuns. 


\section{BIBLIOGRAFIA SOBRE A LITERATURA CHINESA:}

01. BERTUCCIOLI, Giuliano. La Letteratura Cinese. Milano Sansoni- Academia, 1968 .

02. CHOW, Tse-Tsung. The May Fourth Movement. Cambridge, Harvard University Press, 1960.

03. GOLDMAN, Merle (ed.) Modern Chinese Literature in the May Fourth Era. Harvard East Asian Series, 1977

04. HSIA, C. T A History of Modern Chinese Fiction 1917-1957, Yale U.P.

05. Mc CASKEY, M. "Categorization of Chinese Literature" in Language and Linguistics. Washington, Georgetow Press, 1971 no 2, pp. 25/50.

06. Mc DOUGALL, Bonnie S. The Introduction of Western Literary Theories into Modern China 1919-1925. Tokyo, The Centre for East Asian Cultural Studies, 1971.

07 PISCHEL, Enrica Collotti. História da Revolução Chinesa. 2 vol. Lisboa, Publicações Europa-América, 1976.

08. PRUSEK, J. (ed.). Contribution of the study of the rise and development of modern literature in Asia. Prague, Prague Academia, 1970.

09. PRUSEK, J. "A Confrontation of Traditional Oriental Literature with Modern European Literature in the Context of the Chinese Literary Revolution" in Archív Orientální, 32, pp. 365-375. Prague, 1964.

10. PRUSEK, Jaroslav. "Quelques Remarques sur la Nouvelle Littérature Chinoise, in DEMIÉVILLE, Paul, Mélanges de Sinologie. Paris, PUF, 1966, Bibliothèque de l'Institut des Hautes Études Chinoises, vol. XX, pp. 209-223. 